\title{
Noncovalent Protein and Peptide Functionalization of Single-Walled Carbon Nanotubes for Biodelivery and Optical Sensing Applications
}

\author{
Alessandra Antonucci, ${ }^{\dagger}$ Justyna Kupis-Rozmysłowicz, ${ }^{\dagger}$ and Ardemis A. Boghossian* \\ Institute of Chemical Sciences and Engineering (ISIC), École Polytechnique Fédérale de Lausanne (EPFL), 1015-Lausanne,
} Switzerland

ABSTRACT: The exquisite structural and optical characteristics of single-walled carbon nanotubes (SWCNTs), combined with the tunable specificities of proteins and peptides, can be exploited to strongly benefit technologies with applications in fields ranging from biomedicine to industrial biocatalysis. The key to exploiting the synergism of these materials is designing protein/peptide-SWCNT conjugation schemes that preserve biomolecule activity while keeping the near-infrared optical and electronic properties of SWCNTs intact. Since $\mathrm{sp}^{2}$ bondbreaking disrupts the optoelectronic properties of SWCNTs, noncovalent conjugation strategies are needed to interface biomolecules to the nanotube surface for optical biosensing and delivery applications. An underlying understanding of the forces contributing to protein and peptide interaction with the nanotube is thus necessary to identify the appropriate conjugation design rules for specific applications. This article explores the molecular interactions that govern the adsorption of peptides and proteins on SWCNT surfaces, elucidating contributions from individual amino acids as well as secondary and tertiary protein structure and conformation. Various noncovalent conjugation strategies for immobilizing peptides, homopolypeptides, and soluble and membrane proteins on SWCNT surfaces are presented, highlighting studies focused on developing near-infrared optical sensors and molecular scaffolds for self-assembly and biochemical analysis. The analysis presented herein suggests that though direct adsorption of proteins and peptides onto SWCNTs can be principally applied to drug and gene delivery, in vivo imaging and targeting, or cancer therapy, nondirect conjugation strategies using artificial or natural membranes, polymers, or linker molecules are often better suited for biosensing applications that require conservation of biomolecular functionality or precise control of the biomolecule's orientation. These design rules are intended to provide the reader with a rational approach to engineering biomolecule-SWCNT platforms, broadening the breadth and accessibility of both wild-type and engineered biomolecules for SWCNT-based applications.

KEYWORDS: single-walled carbon nanotube (SWCNTs or SWNTs), multi-walled carbon nanotubes (MWCNTs or MWNTs), biomolecules, nanoparticles, bioconjugation, optical nanosensors, near-infrared (nIR) fluorescence

\section{INTRODUCTION}

Since the first characterization of individual single-walled carbon nanotube (SWCNT) fluorescence in 2002, ${ }^{1}$ the following decade has seen an over 600\% surge in SWCNTbased research. SWCNTs have proven to be among the most versatile materials today, enabling a breadth of novel hybrid materials in fields spanning healthcare, ${ }^{2-4}$ molecular biology, 5,6 energy, ${ }^{7,8}$ and catalysis. ${ }^{9}$ A large fraction of this recent research has focused on exploiting intrinsic SWCNT optical properties as a means of signal transduction in bio-optical devices. ${ }^{10-12}$ The indefinite photostability, combined with the singlemolecule sensitivity limits and optical transparency of biological tissue to near-infrared fluorescence, substantiates the increased use of SWCNTs in sensing platforms for a nearly limitless range of applications. ${ }^{11-15}$

By virtue of their highly hydrophobic nature, one of the primary challenges in engineering carbon nanotube-based materials such as SWCNTs and the closely related multi- walled carbon nanotubes (MWCNTs) is overcoming their pronounced tendency to strongly self-associate in water and form thick, insoluble, toxic aggregates. Both covalent and noncovalent sidewall surface functionalization can be used to disperse nanotubes in aqueous solutions to enhance their biocompatibility. However, in the case of SWCNTs, the aggregates demonstrate diminished fluorescence ${ }^{16}$ that compromises not only the use of SWCNTs for optical applications, but also nanotube dispersibility in a manner that hinders their interaction with biological components under physiological conditions. Because covalent functionalization perturbs and even diminishes SWCNT optical properties, ${ }^{17}$ an essential element in the design of optical SWCNT-based devices is the noncovalent conjugation of SWCNTs. Noncovalent function-

Received: January 20, 2017

Accepted: March 16, 2017

Published: March 16, 2017 
alization of nanotubes ${ }^{18}$ has already been rigorously developed for MWCNTs using linker molecules ${ }^{19,20}$ and polymers. $^{21}$ SWCNT functionalization has been similarly achieved with a variety of wrappings such as synthetic ${ }^{22}$ and biopolymers ${ }^{23-26}$ (e.g., DNA, RNA oligonucleotides), peptides, ${ }^{27,28}$ and proteins. $^{29-32}$ These wrappings can stabilize SWCNT dispersions in water without altering the extended $\pi$-conjugated system of the nanotube. ${ }^{33}$

In addition to improved dispersivity, noncovalent wrappings can also impart the SWCNT with secondary characteristics such as molecular selectivity. In this regard, protein- and peptide-based conjugation strategies are particularly advantageous for the development of SWCNT devices that require specific molecular recognition or biocharacterization capabilities. $^{34-36}$ Optical protein-SWCNT technologies developed using these noncovalent conjugation strategies include, for example, enzyme-based optical biosensors for the label-free detection of target analytes. ${ }^{14,37}$ In addition to bioanalyte sensing applications, the high surface area-to-volume ratio and uniform structural integrity of the surface allow the nanotube to behave as a scaffold for protein and peptide immobilization ${ }^{34,38}$ for drug delivery applications. Nanotube fluorescence in this regard has been used to monitor protein self-assembly ${ }^{39}$ and activity. ${ }^{40}$

Most noncovalent immobilization techniques can be broadly categorized into two groups: (i) purely adsorptive and (ii) hybrid approaches (Figure 1). The purpose of this review
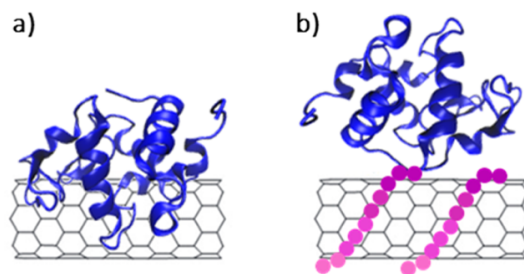

c)

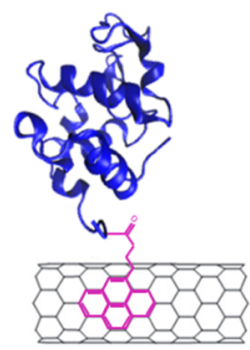

Figure 1. Overview of approaches for noncovalent protein (blue) conjugation to a SWCNT (black): (a) nonspecific physical adsorption of a protein to a SWCNT, (b) hybrid conjugation through covalent attachment to noncovalent wrappings (magenta), and (c) protein binding to heterobifunctional linker molecules (magenta) adsorbed onto SWCNTs. article is to present an overview of the various conjugation strategies in each of these categories. We highlight experimental applications relevant to each strategy and discuss the key underlying forces that govern the nature of the protein/ peptide-SWCNT interactions. These forces contribute to characteristics such as adsorption efficiency, biomolecule orientation, multicomponent self-assembly mechanisms, stability, protein activity, and, ultimately, SWCNT fluorescence response. This understanding is used to identify and optimize appropriate conjugation strategies for different applications.

\section{NONSPECIFIC PROTEIN AND PEPTIDE ADSORPTION}

A survey of the literature on protein/peptide-SWCNT conjugation shows that nonspecific adsorption, because of its simple and generally applicable procedure, is one of the most commonly used strategies for developing novel nanotube-based technologies. Protocols often consist of an ultrasonication step in which carbon nanotubes are individually debundled in solutions containing the desired protein/peptide, followed by ultracentrifugation and filtration to remove remaining aggregates and unbound molecules. Since direct ultrasonication of the protein may result in denaturation, an alternative approach to conjugating SWCNTs is to suspend the SWCNTs in surfactant and then dialyze the surfactant in the presence of the protein/peptide to assist in biomolecule adsorption upon gradual removal of the detergent. ${ }^{37,41}$

As reported by Andrade et al., ${ }^{42}$ every protein presents its own "unique molecular personality", and, depending on the protein structure and scope of application, different parameters need to be taken into account to optimize assembly on the SWCNT surface. The spontaneous association of proteins with SWCNTs occurs when the Gibbs binding free energy is negative $(\Delta G<0) .^{43}$ In contrast to small gas particles, whose symmetric, rigid structures typically give rise to Langmuir-type adsorption behavior, ${ }^{44,45}$ proteins often undergo additional complex phenomena such as conformational rearrangements, changes in orientation, aggregation, and lateral interactions that further complicate the study of their interfacing with substrates. ${ }^{46}$ Stable dispersions are the result of electrostatic or steric repulsion provided by the coating molecules as well as favorable van der Waals, hydrophobic, and $\pi$-stacking interactions at the SWCNT interface dominating over the strong van der Waals attractive forces between the carbon nanotubes. ${ }^{30,47}$
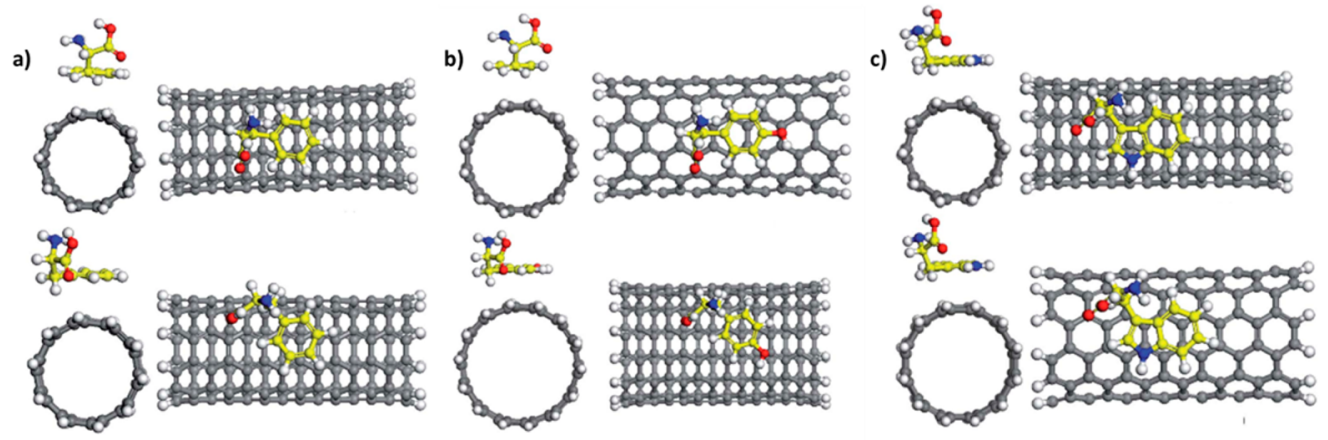

Figure 2. Most stable (a) Phe/(5,5)-SWCNT (top and bottom); (b) Tyr/(6,6)-SWCNT (top), Tyr/(7,7)-SWCNT (bottom); (c) Trp/(6,6)SWCNT (top) and Trp/(7,7)-SWCNT (bottom) complexes in two different views, the front view (left side) and top view (right side). Reproduced with permission from ref 50. Copyright 2011, Royal Society of Chemistry. 
When considering the individual contribution of specific amino acid residues on the total free energy of protein and peptide binding, aromatic amino acid residues are shown to exhibit the strongest affinity for SWCNTs in terms of adsorption efficiency and interaction energy. ${ }^{48}$ Through combined Monte Carlo modeling and in vitro selection techniques such as phage display, Wang et al. ${ }^{49}$ engineered polypeptides capable of recognizing the surface of SWCNTs using consensus binding sequences containing motifs rich in aromatic side chains at specific locations. By investigating the adsorption of aromatic amino acids Phe, Tyr, and Trp onto the SWCNT surface, Wang and co-workers ${ }^{50}$ identified $\pi-\pi$ stacking interactions between the benzene (Phe and Tyr) and indole (Trp) rings of the residues and carbon nanotubes as key interactions in the adsorption process (Figure 2). Of the aromatic residues, Trp and Phe were shown to have the highest and lowest binding affinities toward carbon nanotubes, respectively. ${ }^{51}$ The interaction of His with SWCNTs was found to be weaker than these aromatic amino acids because of the less pronounced aromaticity of its imidazole. ${ }^{48}$

In addition to aromaticity, charge distribution may also contribute to amino acid-SWCNT binding. In fact, one of the most extensively studied model proteins, lysozyme (LSZ), has been shown to solubilize SWCNTs largely through charge interactions between Arg residues in the two loop regions at the SWCNT interface (Figure 3). The guanidinium group at the
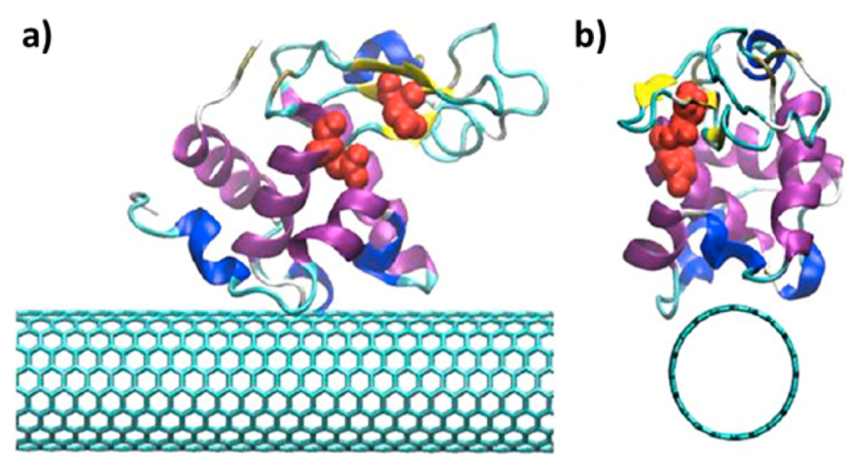

Figure 3. Interaction between the (10,10)-SWCNT and lysozyme from the (a) side and (b) front view. The catalytic residues of the protein is shown in red. Reprinted in part with permission from ref 32. Copyright 2016 American Chemical Society.

end of the Arg side chain strongly binds to aromatic moieties, with cation $-\pi$ interactions dominating on the SWCNT sidewall. $^{52}$ This explains why, in addition to peptides and proteins, positively charged homopolypeptides like poly-Larginine (PLA) have a strong affinity for SWCNTs. ${ }^{27}$ Monomeric amino acids mainly exist as zwitterions in aqueous environments, containing both negatively charged $\left(-\mathrm{COO}^{-}\right)$ and positively charged $\left(-\mathrm{NH}_{3}{ }^{+}\right)$groups. The protonated amine group is predicted to preferentially bind the SWCNT because protonation strengthens the polarity of the amino acid zwitterion. Previous studies have shown that the Gly zwitterion has a stronger affinity to the armchair $(3,3)$-SWCNT than the nonionic Gly, and the adsorption energy of Gly on the SWCNT is comparable to that observed for gas molecules. ${ }^{53,54}$ Moreover, direct exposure of the negatively charged carboxylate and positively charged ammonium groups, which extend away from the nanotube surface and toward the aqueous solution, facilitates the solubilization of SWCNTs in water, likely providing the electrostatic repulsion that prevents SWCNT reaggregation.

Polarity, hydrophobicity, and van der Waals interactions may also aide in the protein- and peptide-based solubilization of SWCNTs. Because these interactions are considered weaker than electronic SWCNT interactions, proteins may require a significant percentage of basic, polar amino acid residues to be able to readily stabilize SWCNTs in aqueous environments (Figure 4). ${ }^{30}$ However, proteins such as histones (HSTs),
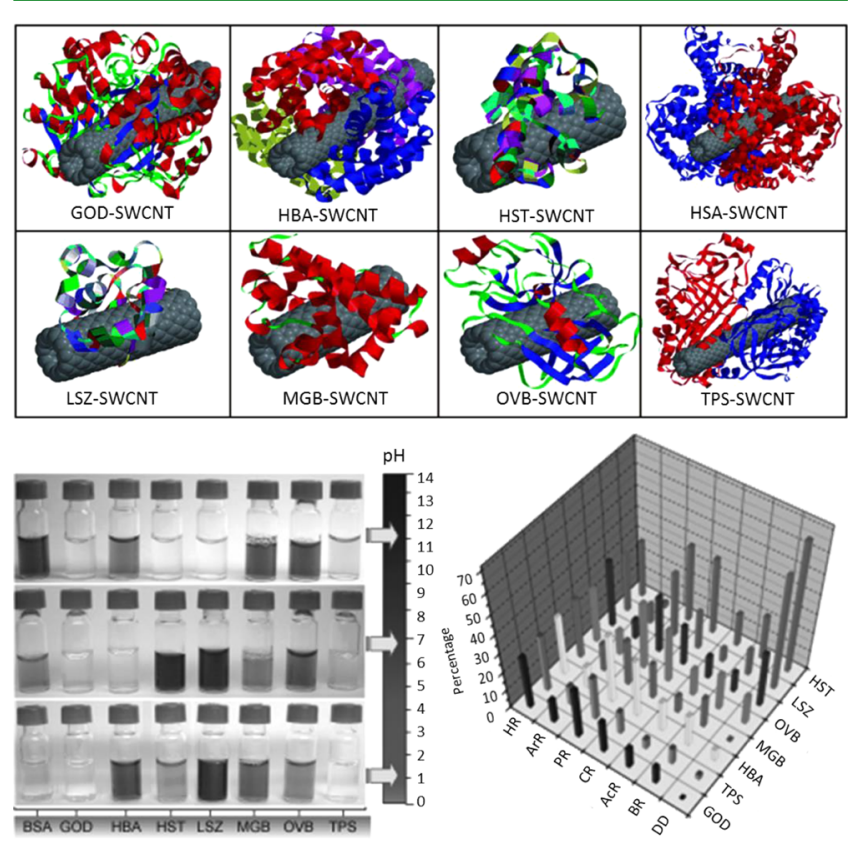

Figure 4. Top: schematic representation of protein-SWCNT complexes: glucose oxidase (GOD), hemoglobin (HBA), histone (HST), human serum albumin (HSA), lysozyme (LSZ), myoglobin (MGB), ovalbumin (OVB), and trypsin (TPS). Bottom, left: stability of the protein-SWCNT dispersions at different $\mathrm{pH}$. Bottom, right: bars illustrating the degree of SWCNT debundling (DD) with respect to the percentage of hydrophobic (HR), aromatic (ArR), polar (PR), charged (CR), acidic (AcR), and basic (BR) residues in the protein. Reproduced with permission from ref 30. Copyright 2007 John Wiley and Sons.

which suspend SWCNTs through polar interactions, may solubilize SWCNTs more efficiently than proteins containing a small number of charged residues, such as glucose oxidase (GOD) or trypsin (TPS). van der Waals interactions between the protein/peptide and SWCNT are often considered relative to changes in SWCNT-SWCNT and SWCNT-water van der Waals interactions. For example, bovine serum albumin (BSA)SWCNT dispersions are largely attributed to the unfavorable interactions between water and the protein-SWCNT interface that accompany the favorable van der Waals interaction between the BSA and SWCNT. Though the hydrophobicity of a protein may improve the protein's interaction with the SWCNT, hydrophobicity contributes to the agglomeration and precipitation of functionalized SWCNTs in aqueous environments. $^{55}$ The formation of these agglomerates may be detrimental to in vivo applications where SWCNT bundling has been shown to result in both cellular and organ toxicity.

Protein adsorption is characterized not only by the individual amino acid contributions discussed above, but also by the secondary and tertiary protein structure. Because of their 
diverse three-dimensional structures, proteins possessing similar distributions of specific residues can interact with SWCNTs in a very different manner. As reported by Matsuura and co-workers, proteins such as papain, pepsin, LSZ, and BSA, which contain similar distributions of hydrophobic, aromatic, and polar residues in the primary sequence, demonstrate considerably distinct binding behaviors. ${ }^{56}$ Analogously, Ge and co-workers studied the adsorption behavior of blood proteins, namely bovine fibrinogen (BFG), gamma globulin ( $\mathrm{Ig}$ ), transferrin (Tf), and BSA, onto SWCNTs. ${ }^{57}$ Although these proteins share a similar percentage of hydrophobic residues, the authors identified a competitive adsorption order, BFG > Ig > Tf $>$ BSA, that positively correlates with the number of contact residues and the binding surface area of the proteins.

2.1. Engineering Protein/Peptide Dispersivity by Tuning Environmental Contributions. Sensing or delivery applications often require a specific protein to be immobilized onto the SWCNT surface. The rational design of glucose sensors, for example, may restrict the selection to glucose sensitive proteins such as GOD and glucose binding proteins where the distribution of aromatic, charged, polar, and hydrophobic residues is largely predetermined. The wild-type distribution of residues may not be suitable for solubilizing SWCNTs through the interactions described above. In such cases, exogenous factors, such as SWCNT morphology and the physiochemistry of the surrounding solution, may be tuned to facilitate solubilization.

The diameter, length, and chirality of the SWCNT have been shown to play a significant role in the amino acid-SWCNT interaction. For example, amino acids show a higher tendency to adsorb on chiral and zigzag SWCNTs compared to armchair SWCNTs. ${ }^{58}$ This observation has been attributed to the higher aromaticity of the zigzag and chiral SWCNTs, which, as discussed above, increases binding affinity. Furthermore, increasing contact area by, for example, increasing the diameter or length of the SWCNT enhances the adsorption energy. ${ }^{50}$ Density functional theory (DFT) and Møller-Plesset secondorder perturbation theory (MP2) calculations have shown that the most preferable geometrical orientation for all aromatic rings is parallel to planar graphene sheets with distances around $3.21,3.33,3.34$, and $3.50 \AA$ for His, Phe, Tyr, and Trp rings, respectively. ${ }^{59}$ Overall, the interaction between the amino acids and graphene was found to be stronger than that for SWCNTs, suggesting that increased curvature disrupts the binding interaction. ${ }^{60,61}$ These calculations have been supported by an observed monotonic decrease in BSA adsorption capacity with increasing nanomaterial curvature (Figure 5). ${ }^{62}$

In addition to noncovalent interactions between the biomolecule and nanotube, environmental conditions such as ionic strength and $\mathrm{pH}$ may also alter protein adsorption. High ionic strength solutions such as cell culture media may subject protein-SWCNT complexes to reaggregation or a reduction in dispersion yield. ${ }^{63}$ Variations in $\mathrm{pH}$ may change the net charges of the amino acid residues, strongly influencing the charge interactions that contribute to protein adsorption. ${ }^{64}$ According to Derjanguin, Landau, Verwey, and Overbeek (DLVO) calculations, ${ }^{65,66}$ a deficiency in the net charge around the isoelectric point (IEP) of the protein results in attraction between suspended SWCNTs, resulting in flocculation. In the case of BSA, different structural conformations are known to depend on $\mathrm{pH}$, shifting from an elongated form ( $\mathrm{E}$ form) under acidic conditions $(\mathrm{pH}<4)$, to a bulky and packed conformation ( $\mathrm{N}$ form) near isoelectric values $(4<\mathrm{pH}<8)$,

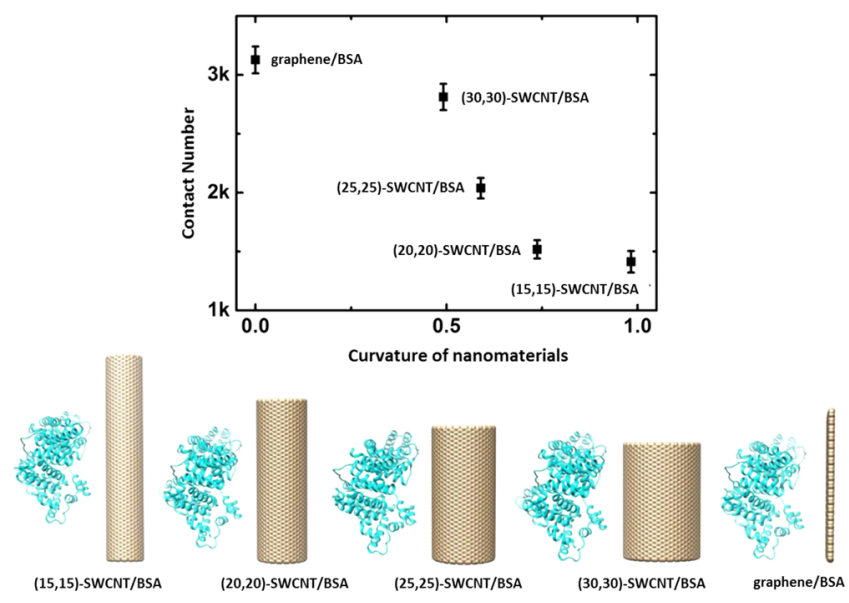

Figure 5. Contact number versus the surface curvature (defined as $c=$ $1 / r$, where $r$ represents the radius of the SWCNT) of carbon-based nanomaterials. Reprinted in part with permission from ref 62 . Copyright 2015 Nature Publishing Group.

to a looser yet bulky conformation (B form) at basic conditions $(\mathrm{pH}>8) .{ }^{67}$ SWCNT dispersion was shown to increase with the bulkiness of the protein conformation and with electrostatic charges for a given amount of bulkiness. In contrast to BSASWCNT, LSZ-wrapped SWCNTs show a strong $\mathrm{pH}$-switching effect that results in the instability of these complexes at $\mathrm{pH}$ values near the IEP of the protein. In the case of LSZ, protonated amine interactions on the sidewalls of the carbon nanotube dominate at $\mathrm{pH}$ values below the IEP of the protein, whereas negative amine adsorption prevails at higher values. According to DLVO theory, the electrostatic repulsive forces at lower and higher $\mathrm{pH}$ stabilize the complexes in aqueous milieu. In contrast, the deficiency of charges around the IEP results in pronounced flocculation in the system.

This ability to tune the agglomeration state of SWCNTs by altering the amino acid composition, combined with the associated changes in photoluminescence, offers a promising platform for developing biological $\mathrm{pH}$ sensors in addition to monitoring the conformational state of a protein. The drop in SWCNT photoluminescence at $\mathrm{pH}$ between 8 and 11 and its recovery at $\mathrm{pH}<8$ and $\mathrm{pH}>11$ can be used to monitor the pH-dependent aggregation state of the LSZ-SWCNT complex. These observations suggest that the stabilization and dispersion mechanisms of protein-SWCNT complexes are protein dependent; while electrostatic interactions play a dominant role in stabilizing LSZ-SWCNT, protein conformation modulates the stability of BSA-SWCNT complexes even at the IEP, where electrostatic repulsion is negligible.

In addition to $\mathrm{pH}$ and ionic strength, protein concentration may also substantially affect the quality of the dispersion. Bundle-free or isolated SWCNTs typically exhibit sharp peaks in the visible and near-infrared regions of the optical absorbance spectra due to the van Hove transitions of metallic and semiconducting SWCNTs. ${ }^{30}$ Broad, weak absorbance peaks often indicate the presence of aggregated SWCNTs, since the van der Waals interactions between stacked tubes disturb the electronic structure of SWCNTs. ${ }^{1}$ Several studies have identified a protein:SWCNT threshold (e.g., 5:1 for BSA:SWCNT) below which a high yield but poor dispersion quality is obtained and above which a higher dispersion, but smaller yield, is obtained. ${ }^{63}$ The unexpected decrease in yield with increasing protein concentration can be explained by the 
protein-mediated depletion attraction phenomenon. Depletion attraction is an entropically driven aggregation force that occurs in colloidal systems containing particles of different sizes. These forces arise from a balance between the translational and orientational entropy of SWCNTs and the translational entropy of the protein. ${ }^{67}$ The presence of excess protein induces attractive intertube forces that reduce the dispersed SWCNT concentration. When additional BSA is added to BSAfunctionalized SWCNTs, the free BSA molecules do not cause SWCNT flocculation. In contrast, the same amount of additional protein added prior to sonication results in SWCNT coagulation. It is believed that the strong BSA-SWCNT binding energy compensates for the depletion forces acting when excess BSA is added after sonication. Horn et al. (2016) observed this protein concentration dependency in the case of LSZSWCNT. ${ }^{68}$ At low LSZ concentrations, a strong van der Waals attraction between the nanotubes dominates, resulting in SWCNT aggregation. However, at higher LSZ:SWCNT ratios, an abrupt transition to an aggregated state is observed, with the loss of SWCNT mixing entropy compensated by an increase in the LSZ translational entropy. Such a transition increases the steady shear viscosity of the solution, and the attractive interactions induce reaggregation of the SWCNTs only when the LSZ concentration is sufficiently large.

2.2. Adsorption Effect on Protein Fold and Activity for Delivery Applications. Protein adsorption may perturb protein structure, or even functionality, a drawback that may pose serious limitations for sensing applications that require a protein's molecular recognition capabilities. In 2004, Karajanagi and co-workers became one of the first groups to study the influence of SWCNTs on the functionality of enzymes such as $\alpha$-chymotrypsin (CT) and soybean peroxidase (SBP), demonstrating that while SBP retained up to $30 \%$ activity upon adsorption, CT retained only $1 \%$ activity. The diminished activity observed for CT was largely attributed to extensive perturbation in the secondary structure of the protein. The disparity in the adsorption effects on protein activity was rationalized from a structural standpoint; SBP contains 19 hydrophobic residues on the surface of the protein that may participate in favorable nanotube interactions. Since these are surface residues, the interaction is not believed to compromise the integrity of the active site that lies on the interior of the protein. On the other hand, CT needs to partially unfold in order to effectively interact with the nanotube surface with its inner residues, a phenomenon that has also been observed for human blood proteins ${ }^{57}$ as well as $\mathrm{LSZ}^{69} .^{70}$

Though SWCNT adsorption may contribute to protein unfolding, under strongly denaturing environments, SWCNT adsorption may actually enhance protein stability. ${ }^{71} \mathrm{SBP}$, for example, which undergoes rapid denaturation at $95{ }^{\circ} \mathrm{C}$, is 10 fold more stable at this elevated temperature once adsorbed onto SWCNTs. It has been hypothesized that the stabilization results from the peculiar curvature of SWCNTs, which suppresses unfavorable protein-protein lateral interactions. Moreover, the increased peptide-backbone conformational freedom at elevated temperatures has been shown to facilitate protein association with SWCNTs. ${ }^{72}$ On the other hand, lack of elevated temperature control during sonication, which is frequently employed as a means of nanotube debundling and functionalization, is likely to result in protein denaturation, thus deeply perturbing its adsorption behavior. ${ }^{56,73}$ Varying sonication times and power can alter protein secondary structure with dramatic consequences for biological applica- tions, as conformational changes may result in the complete loss of protein activity. ${ }^{63,74}$

\section{NONSPECIFIC ADSORPTION OF NATURAL AND SYNTHETIC MEMBRANE FRAGMENTS}

The examples discussed thus far largely hold for soluble proteins that are capable of maintaining their fold in the absence of solubilizing surfactants or lipids. However, many vital proteins function only in a bilayer membrane environment and thus often require additional considerations to provide a viable route for their functional coupling to the SWCNT surface. Artyukhin and co-workers, ${ }^{75}$ for example, modified the SWCNT surface with a hydrophilic polymer cushion layer obtained by layer-by-layer self-assembly of alternating oppositely charged polyelectrolytes such as poly(diallyldimethylammonium chloride) (PDDA), polystyrenesulfonate (PSS), and poly(allylamine hydrochloride) (PAH). This derivatization process was followed by the formation of lipid bilayers through vesicle fusion, yielding a synthetic membrane that can be used to support membrane proteins such as the anthrax protective antigen fragment PA63.

Photoresponsive membrane proteins present an additional constraint that requires the protein to be orientated in a manner that ensures effective charge transfer to the SWCNT. ${ }^{8,39}$ In 2005, Bradley et al. $^{76}$ integrated the cell membrane of Halobacterium salinarum, which harbors photosensitive bacteriorhodopsins (BRhs) that are largely uniformly orientated in the host membrane, in a carbon nanotube-based transistor. Five years later, a sodium cholate suspension-dialysis method was used by Bertoncini et al. ${ }^{77,78}$ to noncovalently immobilize natural purple membranes consisting of lipids and BRhs on the sidewalls of SWCNTs, and the resulting complexes showed $\mathrm{pH}$-dependent energy transfer from the $\mathrm{BRh}$ to the SWCNTs with efficiencies around 94\%. The hydrophobic forces between the $\alpha$-helices and the sidewalls of nanotubes dominate this interaction, and the relatively weak nature of these forces resulted in minimal conformational, and consequently activity, perturbation. Ham and co-workers ${ }^{8,39}$ relied on the use of synthetic lipid bilayer discs called nanodiscs to encapsulate and stabilize purified light-harvesting reaction centers isolated from the photosynthetic purple bacterium, Rhodobacter sphaeroides. In this approach, sodium cholatesuspended carbon nanotubes were dialyzed in the presence of phospholipids, membrane scaffold proteins, and reaction centers. Upon removal of the surfactant, the remaining components spontaneously self-assemble, forming nanodiscs that unidimensionally align along the length of the nanotube with individual proteins embedded within the bilayer discs (Figure 6). The hole injection site, which is located in a relatively hydrophobic domain of the protein, is hypothesized to be directed toward the sidewalls of the SWCNTs, with the

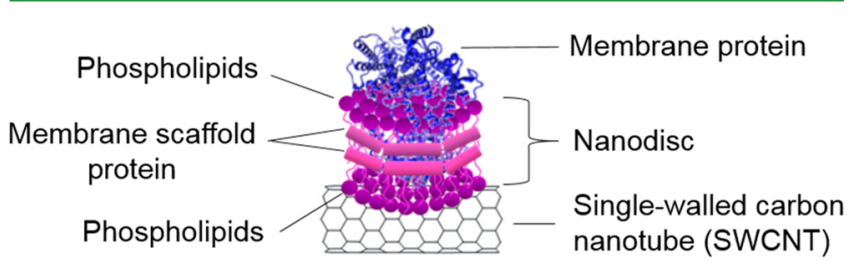

Figure 6. Schematic representation of a synthetic lipid bilayer disc, or nanodisc, embedding a reaction center protein on the surface of a SWCNT. 
a)

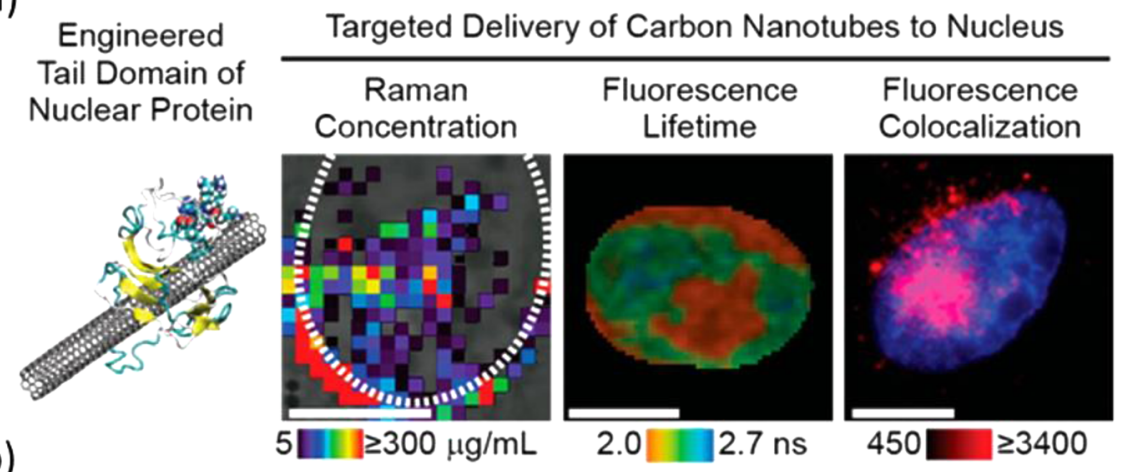

b) 5 WII $\geq 300 \mu \mathrm{g} / \mathrm{mL}$

$2.0 \quad 12.7 \mathrm{~ns}$

$\geq 3400$

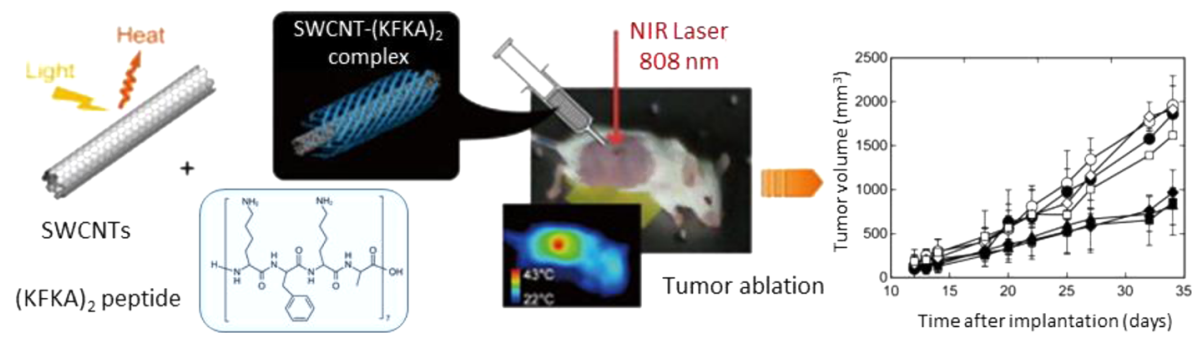

Figure 7. (a) Targeted nuclear delivery of SWCNTs in HeLa cells is facilitated by noncovalently attaching engineered nuclear proteins LB1. (b) Peptide-SWCNT composites are injected in tumor cells and used in photothermal cancer therapy. Reproduced with permission from refs 93 and 94. Copyright 2016, American Chemical Society. Copyright 2013 Elsevier.

hydrophilic globular portion of the protein exposed to the external solution.

\section{HYBRID APPROACH: COVALENT ATTACHMENT TO NONCOVALENT WRAPPINGS}

The enzymatic activity and intrinsic selectivity of most proteins often require the nearly complete retention of their native fold, ${ }^{79}$ and, as discussed above, the hydrophobic surface of SWCNTs provides a fundamentally divergent environment that may perturb structure and functionality in a protein-specific manner. ${ }^{80}$ An alternative bioconjugation strategy that offers more control over protein orientation while circumventing the structural perturbation caused by direct adsorption is the hybrid noncovalent/covalent approach (Figure 1b, c). In one approach, the SWCNT is noncovalently covered by a synthetic or biological polymer that is covalently conjugated to the protein (Figure 1b). For example, Kim and co-workers ${ }^{81}$ functionalized the SWCNT surface with phospholipid polymers containing carboxylated poly(ethylene glycol) (cPVA), which was covalently tethered to D-luciferase through a carbodiimideactivated cross-linking reaction to create an optical ATP sensor. ATP is selectively consumed by luciferase in a two-step bioluminescent reaction that quenches SWCNT fluorescence in living cells, enabling spatial cellular ATP detection with a detection limit of $240 \mathrm{nM}$. A similar conjugation approach was used to immobilize glucose binding protein (GBP), which is a periplasmic binding protein that undergoes a significant conformational change upon binding its target analyte, glucose. This platform was used to create a reversible optical glucose sensor for continuous blood sugar monitoring. ${ }^{40,82}$ This conjugation strategy relies on the covalent conjugation of a Lys residue on the GBP to carboxylated poly(vinyl alcohol) (PVA)-wrapped SWCNTs through amide bond formation. Compared to GBP physisorption, the additional degrees of rotational and translational freedom allow the protein to behave as a nanoscale actuator, modulating the fluorescence signal in response to glucose. In addition to PVA, other polymers that have been used to conjugate SWCNTs include poly ethylene oxide (PEO) derivatives, which have been shown to reduce the nonspecific adsorption of proteins while enabling the selective recognition of target molecules of interest, ${ }^{83}$ and pluronic P103, a triblock copolymer with hydrophilic PEO segments that leave the SWCNT surface with hydrophilic, charge-neutral characteristics that suppress nonspecific binding to the SWCNT surface. These polymers have been key in developing highly specific electronic sensors for the detection of clinically relevant biomolecules such as antibodies. ${ }^{84}$

Heterobifunctional cross-linking agents may be used as an alternative conjugation approach (Figure 1c). The cross-linking agents often contain an aromatic moiety that can interact with the $\pi$-network of SWCNTs and at least one functional group that can be used to selectively bind desired protein target residues, such as Lys or Cys. The amino acid-specific functional group helps control protein orientation by limiting the total possible number of accessible sites on the protein. The most common commercially available derivative used is 1-pyrenebutyric acid $N$-hydroxysuccinimide ester, which contains terminal groups that are highly reactive to nucleophilic substitution by primary and secondary amines that are abundantly present on the surface of most proteins. This technique enables the immobilization of a wide range of biomolecules on the sidewalls of SWCNTs, ensuring both high specificity and efficiency, as demonstrated by Chen and co-workers with ferritin, streptavidin, and biotinil-3,6-dioxaoctanediamine ${ }^{85}$ and by Besteman et al. with GOD. ${ }^{86}$ Carbon nanotubes were also noncovalently functionalized with 1-aminopyrene and used for immobilizing laccase via a glutaraldehyde cross-linking reaction. ${ }^{87}$ Surfactant molecules may also behave as chemical linkers, adsorbing to the SWCNT surface primarily through hydrophobic interactions. Suma and co-workers, for example, used Triton X-100-functionalized nanotubes to immobilize a recombinant deoxygenase that catalyzes the ring cleavage of 
various aromatic hydrocarbons. ${ }^{88}$ The conjugated enzyme demonstrated increased enzyme stability with varying $\mathrm{pH}$, temperature, and ionic strength, maintaining activities as high as $60-79 \%$.

Fusion proteins with terminal-linked peptides may also enable orientation-controlled protein conjugation while minimizing the interfacial interaction with the polyaromatic surface of the SWCNT. Chen et al. ${ }^{89}$ conjugated carbonic anhydrase to the SWCNT surface by linking the C-terminus of the protein to a specific peptide sequence that has been screened by phage display to possess a very high binding affinity toward SWCNTs. ${ }^{90}$ This approach not only improved the binding efficiency of the carbonic anhydrase by a factor of 20, but also largely retained undisrupted protein structure.

\section{ENGINEERING RULES FOR BIOMOLECULE-SWCNT APPLICATIONS}

The last ten years have seen significant advancements in biomolecule immobilization strategies that have improved the accessibility of previously intractable applications, particularly in the biomedical field. Depending on the importance of parameters such as protein orientation, protein activity, SWCNT fluorescence sensitivity, and SWCNT dispersion, the different conjugation strategies presented in this review offer a modular approach to engineering nanohybrid complexes for specific applications.

Because of their simple and generally reversible nature, conjugation methods based on nonspecific adsorption have been widely employed for delivery and cancer treatment applications. The high aspect ratio and surface area of SWCNTs, combined with the increased biocompatibility of protein/peptide-SWCNT complexes (e.g., no immune or acute inflammatory responses ${ }^{57,91}$ ), favor stable dispersions that are beneficial as alternative multifunctional biological transporters for oligonucleotide and drug delivery, ${ }^{55}$ in vivo subcellular targeting and imaging, ${ }^{91-93}$ or near-infrared light-based therapy of cancer ${ }^{94}$ (Figure 7). Significant advancements in both the experimental and computational fronts over the past several years have helped elucidate the contributions of not only individual amino acid residues and larger protein domains, but also factors such as SWCNT topology on the adsorption process. These principles have been used to design amphiphilic polypeptides containing cationic groups that can efficiently bind nucleic acids, allowing SWCNTs to behave as efficient gene delivery scaffolds. ${ }^{55}$ Targeted nuclear delivery of SWCNTs in $\mathrm{HeLa}$ cells has been achieved by noncovalently adsorbing engineered nuclear proteins, such as the tail domain of lamin $\mathrm{B1}$ (LB1) that is capable of penetrating the cell membrane (Figure 7a). LB1's relatively small size (molecular weight of 22 $\mathrm{kDa}$ ) and hydrophobic core are ideal for dispersing nanotubes. Simulations have shown that the lowest energetic configuration is achieved when the SWCNT is positioned in the central proteic core, which is possible after protein unfolding and refolding around the tube during sonication or when the LB1 laterally interacts with SWCNT. Since the nuclear core is positioned away from the nanotube, adsorption does not significantly compromise the targeted delivery. ${ }^{93}$ Using a combination of aromatic, charged, and nonpolar residues, peptide engineering has also been used to disperse SWCNTs for photothermal cancer therapy (Figure 7b). Near-infrared irradiation of peptide-functionalized SWCNTs incubated with colon 26 and HepG 2 cells resulted in significant cell damage, and irradiation of colon 26 tumors injected with the SWCNTs showed rapid temperature increases and suppression of tumor growth.

SWCNT intrinsic near-infrared fluorescence, which is preserved after protein physisorption, also enables real-time in vivo tracking of the molecular carriers, allowing improved elucidation of the main delivery pathways in eukaryotic cells. BSA-dispersed SWCNTs, for example, are readily taken up by human cells, showing distinct subcellular localizations. ${ }^{91}$ The observed distribution to and around the nucleus with no significant harmful cellular effects suggests possible applications in gene delivery and selective targeting. The same scaffolds have also been applied for in vivo imaging of Drosophila larvae, allowing a more comprehensive study of subcellular trafficking and biodistribution of nanoparticles in intact living organisms. ${ }^{92}$

When long-lasting direct protein adsorption on SWCNTs is desired, particularly for difficult uptake pathways, exogenous factors can be used to prolong dispersion stability. Since parameters such as $\mathrm{pH}$ and ionic strength are largely controlled by the cellular environment, the strategic selection of SWCNT chirality, in addition to the amino acid sequence, become the primary means of tuning dispersivity. As discussed above, previous studies have shown an overall enhancement in biomolecule binding with increasing SWCNT diameters, and immobilizing the protein or peptide on large diameter SWCNTs may improve stability. Although precise SWCNT diameter separation remains an ongoing area of active research, multiple established protocols are available for biasing the distribution of SWCNTs toward large diameter tubes. ${ }^{23,95-97}$

The aforementioned examples benefit from several key characteristics that are conducive only to physisorption applications. For example, LB1 was shown to undergo significant structural changes on the SWCNT surface that may be deleterious to sensing or delivery applications that require preserved protein activity. Further, though an adsorbed conformation with a global energy minimum is favored, proteins may also assume conformations that reflect a local energy minimum, especially under kinetically limiting adsorption conditions. These conditions would introduce conformational heterogeneity to the solution mixture that limits its use in sensing or bioelectronic devices requiring a precise protein orientation on the tube surface. ${ }^{98,99}$ Some applications require nearly wild-type protein sequences that yield poor SWCNT dispersivity even for large diameter SWCNTs, and constraints in the number and location of aromatic or charged amino acid substitutions may limit the solubility of the complex. Since environmental factors such as $\mathrm{pH}$ and ionic strength may also alter adsorption, applications that require the exposure of SWCNT complexes to a wide range of in vivo conditions are particularly challenging for protein-SWCNT complexes with limited bioengineerability. Considering that the stability of these dispersions is limited by the gradual loss of physisorbed proteins as the solution moves toward the formation of the more thermodynamically favored SWCNT bundles, ${ }^{8}$ physisorbed complexes are often better suited for short-term applications.

In cases where a protein can only function when embedded in a membrane bilayer, either native membrane fragments or synthetic biomimetic membranes can be interfaced with the SWCNT to ensure that the protein integrity remains intact upon adsorption. This approach is hypothesized to promote more uniform control of protein orientation, which is extremely important for specific sensing or bioelectronic devices. Although this strategy offers one solution to stabilizing the 
membrane protein structure, the versatility of these platforms is limited to membrane proteins of specific sizes and geometries. Physisorption places proteins in close proximity to the hydrophobic SWCNT surface, which, depending on the nature of the biomolecule, may compromise the protein's structure and functionality. ${ }^{80,100}$ The fewer degrees of freedom available to an adsorbed protein, combined with suboptimal orientation or adsorption-induced conformational alterations, may result in loss of protein specificity or activity. ${ }^{80}$ The use of natural membrane fragments for suspending SWCNTs offers a much more direct approach to immobilizing membrane proteins, circumventing the need to reconstitute a synthetic membrane and benefiting from an inherent protein environment that has been optimized by nature. However, as is the case with purified protein adsorption, one drawback of using natural membrane fragments is the heterogeneity of nonspecifically adsorbed complexes and nonuniform protein distribution. Although natural and synthetic membranes offer one solution to stabilizing membrane protein structure in an oriented monolayer, the versatility of these self-assembly platforms is limited to membrane proteins of specific sizes and geometries. Self-assembly parameters such as dialysis rate, phospholipid composition, and membrane scaffold protein length would need to be optimized for proteins that have not already been integrated into this platform.

Hybrid conjugation approaches offer a more versatile, albeit more complex, conjugation approach to immobilizing proteins. Covalent protein functionalization from an individual site increases the degrees of freedom compared to complete adsorption, helping to minimize structural perturbation caused by direct adsorption. These approaches are especially suitable for SWCNT-based sensing applications that benefit from the protein's increased conformational freedom. In such applications, the protein's conformational change upon binding specific analytes may modulate the near-infrared fluorescence of SWCNTs, enabling the optical detection of target molecules such as glucose $\mathrm{e}^{40}$ and $\mathrm{ATP}^{81}$ at very low concentrations. Some sensing applications may also require coating SWCNTs with synthetic polymers or surfactants prior to protein immobilization when it is necessary to suppress or minimize nonspecific protein binding. ${ }^{101}$ Certain in vivo cellular targeting applications may also require covalent protein attachment onto nanostructured vehicles. In the study performed by Neves et al., the human protein annexin $\mathrm{V}$, which is known to selectively bind phospholipids expressed externally on tumor cells, was conjugated to SWCNTs using an intermediate linker. ${ }^{102}$ This stable platform was successfully used to treat breast cancer using near-infrared photothermal therapy. In an orthogonal approach to enhancing the specificity of a cancer drug delivery system, epidermal growth factor (EGF) was attached to the SWCNT through a biopolymer chitosan wrapping and was subsequently targeted by corresponding receptors overexpressed on the surface of cancer cells. ${ }^{103}$ Mitomycin C was also conjugated to SWCNTs using a noncovalent/covalent hybridization approach and used for antitumor drug delivery. ${ }^{104}$ In this particular platform, an engineered peptide directly suspended the SWCNTs, and the complex was subsequently covalently conjugated to mitomycin $\mathrm{C}$. Covalent conjugation was used to moderate the $\mathrm{pH}$-dependent controlled release of mitomycin $\mathrm{C}$ after cellular uptake.

\section{CONCLUSIONS AND OUTLOOK}

To date, nanobiomaterials such as protein/peptide-SWCNTs have been largely developed and optimized using a materials engineering approach. Historically, most of these techniques have focused on engineering bioconjugative chemistries and tuning nanomaterial properties. However, the relatively recent advancements in gene synthesis, decreasing DNA sequencing costs, and increasing primer accessibility have all enabled a complementary, protein engineering approach that will likely play a larger role in future bioconjugative strategies. The examples described above touch upon several instances whereby site-specific mutagenesis or SWCNT-binding sequence domains are used to target protein conjugation sites. Beyond enabling bioconjugation, protein engineering allows one to not only improve protein activity in the presence of the nanoparticle, but also altogether alter protein behavior by engineering entire protein domains. Researchers are no longer confined to only interfacing proteins nature has provided; advancements in molecular biology allow them to tune or even create new proteins with unique functions. These techniques can be used to engineer proteins with improved or altered functionalities in the presence of SWCNTs. In addition to sensing analytes of interest through analyte-protein interactions, bioengineering provides a powerful platform for screening protein-protein, protein-oligonucleotide, and oligonucleotide-oligonucleotide interactions, as well as for screening protein functionality or response toward specific analytes. Existing screening approaches, such as ELISA, may benefit from sensing platforms based on intrinsic, near-infrared SWCNT fluorescence, which obviates additional labeling steps required to obtain a photometric signal. This ability to simultaneously tune protein behavior alongside the nanoparticle properties opens the doors to a whole new level of tunability with an unprecedented reach toward designing more selective, efficient, and sensitive SWCNT-based devices for a wide spectrum of applications.

\section{AUTHOR INFORMATION}

\section{Corresponding Author}

*E-mail: ardemis.boghossian@epfl.ch.

\section{Author Contributions}

${ }^{\dagger}$ A.A. and J.K.-R. contributed equally. A.A., J.K.-R., and A.A.B. all contributed to the literature review and writing of this manuscript. All authors have given approval to the final version of the manuscript.

Notes

The authors declare no competing financial interest.

\section{ACKNOWLEDGMENTS}

The authors would like to acknowledge support from the Swiss National Science Foundation (SNSF) Grant No. 154269.

\section{ABBREVIATIONS}

$$
\begin{aligned}
& \mathrm{CT}=\alpha \text {-chymotrypsin } \\
& \mathrm{ATP}=\text { adenosine triphosphate } \\
& \mathrm{Arg}=\text { arginine } \\
& \mathrm{BRh}=\text { bacteriorhodopsin } \\
& \mathrm{BFG}=\text { bovine fibrinogen } \\
& \mathrm{BSA}=\text { bovine serum albumin } \\
& \mathrm{cPVA}=\text { carboxylated poly }(\text { ethylene glycol }) \\
& \text { Cys = cysteine } \\
& \text { DFT = density functional theory }
\end{aligned}
$$


DNA $=$ DNA

DLVO = Derjanguin, Landau, Verwey, and Overbeek

$\mathrm{EGF}=$ epidermal growth factor

ELISA = enzyme-linked immunosorbent assay

Ig = gamma globulin

$\mathrm{GBP}=$ glucose-binding protein

$\mathrm{GOD}=$ glucose oxidase

Gly = glycine

HBA = hemoglobin

His = histidine

HST $=$ histone

HSA = human serum albumin

IEP $=$ isoelecric point

$\mathrm{LB} 1$ = lamin $\mathrm{B} 1$

Lys $=$ lysine

$\mathrm{LSZ}=$ lysozyme

MGB = myoglobin

MWCNT = multi-walled carbon nanotube

MP2 = Møller-Plesset second-order perturbation

$\mathrm{OVB}=$ ovalbumin

Phe = phenylalanine

$\mathrm{PAH}=$ poly(allylamine hydrochloride)

PDDA $=\operatorname{poly}($ diallyldimethylammonium chloride $)$

$\mathrm{PEO}=$ poly ethylene oxide

PLA = poly-L-arginine

PSS = polystyrenesulfonate

PVA $=$ poly (vinyl alcohol $)$

RNA $=$ ribonucleic acid

SWCNT = single-walled carbon nanotube

SBP $=$ soybean peroxidase

$\mathrm{Tf}=$ transferrin

TPS $=$ trypsin

Trp = tryptophan

Tyr $=$ tyrosine

\section{REFERENCES}

(1) Connell, M. J. O.; Bachilo, S. M.; Huffman, C. B.; Moore, V. C.; Strano, M. S.; Haroz, E. H.; Rialon, K. L.; Boul, P. J.; Noon, W. H.; Kittrell, C.; Ma, J.; Hauge, R. H.; Weisman, R. B.; Smalley, R. E. Band Gap Fluorescence from Individual Single-Walled Carbon Nanotubes. Science 2002, 297 (5581), 593-596.

(2) Bhirde, A. A.; Patel, V.; Gavard, J.; Zhang, G.; Sousa, A. a; Masedunskas, A.; Leapman, R. D.; Weigert, R.; Gutkind, J. S.; Rusling, J. F. NIH Public Access. ACS Nano 2009, 3 (2), 307-316.

(3) Jain, A.; Homayoun, A.; Bannister, C. W.; Yum, K. Single-Walled Carbon Nanotubes as near-Infrared Optical Biosensors for Life Sciences and Biomedicine. Biotechnol. J. 2015, 10, 447-459.

(4) Zhang, J.; Kruss, S.; Hilmer, A. J.; Shimizu, S.; Schmois, Z.; De La Cruz, F.; Barone, P. W.; Reuel, N. F.; Heller, D. A.; Strano, M. S. A Rapid, Direct, Quantitative, and Label-Free Detector of Cardiac Biomarker Troponin T Using Near-Infrared Fluorescent Single-Walled Carbon Nanotube Sensors. Adv. Healthcare Mater. 2014, 3 (3), 412423.

(5) Wang, X.; Liu, Z. Carbon Nanotubes in Biology and Medicine: An Overview. Chin. Sci. Bull. 2012, 57 (2-3), 167-180.

(6) Yang, W.; Thordarson, P.; Gooding, J. J.; Ringer, S. P.; Braet, F. Carbon Nanotubes for Biological and Biomedical Applications. Nanotechnology 2007, 18 (41), 412001.

(7) Boghossian, A. A.; Sen, F.; Gibbons, B. M.; Sen, S.; Faltermeier, S. M.; Giraldo, J. P.; Zhang, C. T.; Zhang, J.; Heller, D. A.; Strano, M. S. Application of Nanoparticle Antioxidants to Enable Hyperstable Chloroplasts for Solar Energy Harvesting. Adv. Energy Mater. 2013, 3 (7), 881-893.

(8) Boghossian, A. A.; Choi, J. H.; Ham, M. H.; Strano, M. S. Dynamic and Reversible Self-Assembly of Photoelectrochemical
Complexes Based on Lipid Bilayer Disks, Photosynthetic Reaction Centers, and Single-Walled Carbon Nanotubes. Langmuir 2011, 27 (5), 1599-1609.

(9) Yan, Y.; Miao, J.; Yang, Z.; Xiao, F.-X.; Yang, H. B.; Liu, B.; Yang, Y. Carbon Nanotube Catalysts: Recent Advances in Synthesis, Characterization and Applications. Chem. Soc. Rev. 2015, 44 (10), 3295-3346.

(10) Boghossian, A. A.; Zhang, J.; Barone, P. W.; Reuel, N. F.; Kim, J. H.; Heller, D. A.; Ahn, J. H.; Hilmer, A. J.; Rwei, A.; Arkalgud, J. R.; Zhang, C. T.; Strano, M. S. Near-Infrared Fluorescent Sensors Based on Single-Walled Carbon Nanotubes for Life Sciences Applications. ChemSusChem 2011, 4 (7), 848-863.

(11) Kruss, S.; Hilmer, A. J.; Zhang, J.; Reuel, N. F.; Mu, B.; Strano, M. S. Carbon Nanotubes as Optical Biomedical Sensors. Adv. Drug Delivery Rev. 2013, 65 (15), 1933-1950.

(12) Li, C.; Shi, G. Carbon Nanotube-Based Fluorescence Sensors. J. Photochem. Photobiol., C 2014, 19 (1), 20-34.

(13) Liu, Z.; Tabakman, S. M.; Chen, Z.; Dai, H. Preparation of Carbon Nanotube Bioconjugates for Biomedical Applications. Nat. Protoc. 2009, 4 (9), 1372-1381.

(14) Barone, P. W.; Parker, R. S.; Strano, M. S. In Vivo Fluorescence Detection of Glucose Using a Single-Walled Carbon Nanotube Optical Sensor: Design, Fluorophore Properties, Advantages, and Disadvantages. Anal. Chem. 2005, 77 (23), 7556-7562.

(15) Yum, K.; McNicholas, T. Single-Walled Carbon NanotubeBased Near-Infrared Optical Glucose Sensors toward In Vivo Continuous Glucose Monitoring. J. Diabetes Sci. Technol. 2013, 7 (1), 72-87.

(16) Battigelli, A.; Ménard-Moyon, C.; Da Ros, T.; Prato, M.; Bianco, A. Endowing Carbon Nanotubes with Biological and Biomedical Properties by Chemical Modifications. Adv. Drug Delivery Rev. 2013, 65 (15), 1899-1920.

(17) Sapsford, K. E.; Algar, W. R.; Berti, L.; Gemmill, K. B.; Casey, B. J.; Oh, E.; Stewart, M. H.; Medintz, I. L. Functionalizing Nanoparticles with Biological Molecules: Developing Chemistries That Facilitate Nanotechnology. Chem. Rev. 2013, 113 (3), 1904-2074.

(18) Wu, B.; Kuang, Y.; Zhang, X.; Chen, J. Noble Metal Nanoparticles/carbon Nanotubes Nanohybrids: Synthesis and Applications. Nano Today 2011, 6 (1), 75-90.

(19) Ou, Y.; Huang, M. H. High-density assembly of gold nanoparticles on multiwalled carbon nanotubes using 1-pyrenemethylamine as interlinker. J. Phys. Chem. B 2006, 110, 2031-2036.

(20) Wang, S.; Wang, X.; Jiang, S. P. PtRu Nanoparticles Supported on 1-Aminopyrene-Functionalized Multiwalled Carbon Nanotubes and Their Electrocatalytic Activity for Methanol Oxidation. Langmuir 2008, 24 (18), 10505-10512.

(21) Wu, B.; Hu, D.; Kuang, Y.; Liu, B.; Zhang, X.; Chen, J. Functionalization of Carbon Nanotubes by an Ionic-Liquid Polymer: Dispersion of Pt and PtRu Nanoparticles on Carbon Nanotubes and Their Electrocatalytic Oxidation of Methanol. Angew. Chem., Int. Ed. 2009, 48 (26), 4751-4754.

(22) Fujigaya, T.; Nakashima, N. Non-Covalent Polymer Wrapping of Carbon Nanotubes and the Role of Wrapped Polymers as Functional Dispersants. Sci. Technol. Adv. Mater. 2015, 16 (2), 024802.

(23) Zheng, M.; Jagota, A.; Semke, E. D.; Diner, B. A.; Mclean, R. S.; Lustig, S. R.; Richardson, R. E.; Tassi, N. G. DNA-Assisted Dispersion and Separation of Carbon Nanotubes. Nat. Mater. 2003, 2 (5), 338342.

(24) Sánchez-Pomales, G.; Cabrera, C. R.; Pagan-Miranda, C.; Santiago-Rodriguez, L. DNA-Wrapped Carbon Nanotubes: From Synthesis to Applications. Carbon Nanotubes 2010, 721-749.

(25) Kupis-Rozmysłowicz, J.; Antonucci, A.; Boghossian, A. A. Review-Engineering the Selectivity of the DNA-SWCNT Sensor. ECS J. Solid State Sci. Technol. 2016, 5 (8), M3067-M3074.

(26) Landry, M. P.; Vuković, L.; Kruss, S.; Bisker, G.; Landry, A. M.; Islam, S.; Jain, R.; Schulten, K.; Strano, M. S. Comparative Dynamics and Sequence Dependence of DNA and RNA Binding to Single Walled Carbon Nanotubes. J. Phys. Chem. C 2015, 119 (18), 1004810058 . 
(27) Hirano, A.; Tanaka, T.; Kataura, H.; Kameda, T. Arginine Side Chains as a Dispersant for Individual Single-Wall Carbon Nanotubes. Chem. - Eur. J. 2014, 20, 4922-4930.

(28) Samarajeewa, D. R.; Dieckmann, G. R.; Nielsen, S. O.; Musselman, I. H. Modifying the Electronic Properties of SingleWalled Carbon Nanotubes Using Designed Surfactant Peptides. Nanoscale 2012, 4 (15), 4544.

(29) Karajanagi, S. S.; Yang, H.; Asuri, P.; Sellitto, E.; Dordick, J. S.; Kane, R. S. Protein-Assisted Solubilization of Single-Walled Carbon Nanotubes. Langmuir 2006, 22 (4), 1392-1395.

(30) Nepal, D.; Geckeler, K. E. Proteins and Carbon Nanotubes: Close Encounter in Water. Small 2007, 3 (7), 1259-1265.

(31) Pagán, M.; Suazo, D.; del Toro, N.; Griebenow, K. A Comparative Study of Different Protein Immobilization Methods for the Construction of an Efficient Nano-Structured Lactate OxidaseSWCNT-Biosensor. Biosens. Bioelectron. 2015, 64, 138-146.

(32) Calvaresi, M.; Zerbetto, F. The Devil and Holy Water: Protein and Carbon Nanotube Hybrids. Acc. Chem. Res. 2013, 46 (11), 24542463.

(33) Tuncel, D. Non-Covalent Interactions between Carbon Nanotubes and Conjugated Polymers. Nanoscale 2011, 3 (9), 35453554

(34) Oliveira, S. F.; Bisker, G.; Bakh, N. A.; Gibbs, S. L.; Landry, M. P.; Strano, M. S. Protein Functionalized Carbon Nanomaterials for Biomedical Applications. Carbon 2015, 95, 767-779.

(35) Marchesan, S.; Prato, M. Under the Lens: Carbon Nanotube and Protein Interaction at the Nanoscale. Chem. Commun. 2015, 51 (21), 4347-4359.

(36) Saifuddin, N.; Raziah, A. Z.; Junizah, A. R. Carbon Nanotubes A Review on Structure and Their Interaction with Proteins. J. Chem. 2013, 2013, 1-18.

(37) Barone, P. W.; Baik, S.; Heller, D. A.; Strano, M. S. NearInfrared Optical Sensors Based on Single-Walled Carbon Nanotubes. Nat. Mater. 2005, 4 (1), 86-92.

(38) Feng, W.; Ji, P. Enzymes Immobilized on Carbon Nanotubes. Biotechnol. Adv. 2011, 29 (6), 889-895.

(39) Ham, M.-H.; Choi, J. H.; Boghossian, A. A.; Jeng, E. S.; Graff, R. A.; Heller, D. A.; Chang, A. C.; Mattis, A.; Bayburt, T. H.; Grinkova, Y. V.; Zeiger, A. S.; Van Vliet, K. J.; Hobbie, E. K.; Sligar, S. G.; Wraight, C. A.; Strano, M. S. Photoelectrochemical Complexes for Solar Energy Conversion That Chemically and Autonomously Regenerate. Nat. Chem. 2010, 2 (11), 929-929.

(40) Yoon, H.; Ahn, J. H.; Barone, P. W.; Yum, K.; Sharma, R.; Boghossian, A. A.; Han, J. H.; Strano, M. S. Periplasmic Binding Proteins as Optical Modulators of Single-Walled Carbon Nanotube Fluorescence: Amplifying a Nanoscale Actuator. Angew. Chem., Int. Ed. 2011, 50 (8), 1828-1831.

(41) Tsai, T. W.; Heckert, G.; Neves, L. F.; Tan, Y.; Kao, D. Y.; Harrison, R. G.; Resasco, D. E.; Schmidtke, D. W. Adsorption of Glucose Oxidase onto Single-Walled Carbon Nanotubes and Its Application in Layer-by-Layer Biosensors. Anal. Chem. 2009, 81 (19), $7917-7925$

(42) Andrade, J. D.; Hlady, V.; Wei, A. P. Adsorption of Complex Proteins at Interfaces. Pure Appl. Chem. 1992, 64 (11), 1777-1781.

(43) Olsson, T. S. G.; Williams, M. A.; Pitt, W. R.; Ladbury, J. E. The Thermodynamics of Protein-Ligand Interaction and Solvation: Insights for Ligand Design. J. Mol. Biol. 2008, 384 (4), 1002-1017.

(44) Rabe, M.; Verdes, D.; Seeger, S. Understanding Protein Adsorption Phenomena at Solid Surfaces. Adv. Colloid Interface Sci. 2011, 162 (1-2), 87-106.

(45) Langmuir, I. Vapor Pressures, Evaporation, Condensation and Adsorption. J. Am. Chem. Soc. 1932, 54 (1918), 2798-2832.

(46) Lynch, I.; Dawson, K. A. Protein-Nanoparticle Interactions. Nano Today 2008, 3 (1-2), 40-47.

(47) Hilding, J.; Grulke, E. A.; Zhang, Z. G.; Lockwood, F. Dispersion of Carbon Nanotubes in Liquids. J. Dispersion Sci. Technol. 2003, 24 (1), 1-41.
(48) He, Z.; Zhou, J. Probing Carbon Nanotube-amino Acid Interactions in Aqueous Solution with Molecular Dynamics Simulations. Carbon 2014, 78, 500-509.

(49) Wang, S.; Humphreys, E. S.; Chung, S.-Y.; Delduco, D. F.; Lustig, S. R.; Wang, H.; Parker, K. N.; Rizzo, N. W.; Subramoney, S.; Chiang, Y.-M.; Jagota, A. Peptides with Selective Affinity for Carbon Nanotubes. Nat. Mater. 2003, 2 (3), 196-200.

(50) Wang, C.; Li, S.; Zhang, R.; Lin, Z. Adsorption and Properties of Aromatic Amino Acids on Single-Walled Carbon Nanotubes. Nanoscale 2012, 4 (4), 1146-1153.

(51) Xie, H.; Becraft, E. J.; Baughman, R. H.; Dalton, A. B.; Dieckmann, G. R. Ranking the Affinity of Aromatic Residues for Carbon Nanotubes by Using Designed Surfactant Peptides. J. Pept. Sci. 2008, 14 (10), 139-151.

(52) Wu, E.; Coppens, M.-O.; Garde, S. Role of Arginine in Mediating Protein-Carbon Nanotube Interactions. Langmuir 2015, 31 (5), 1683-1692.

(53) Peng, S.; Cho, K. Chemical Control of Nanotube Electronics. Nanotechnology 2000, 11 (2), 57-60.

(54) Zhao, J.; Buldum, A.; Han, J.; Lu, J. P. Gas Molecule Adsorption in Carbon Nanotubes and Nanotube Bundles. Nanotechnology 2002, 13 (2), 195-200

(55) Sanz, V.; Coley, H. M.; Silva, S. R. P.; McFadden, J. Modeling the Binding of Peptides on Carbon Nanotubes and Their Use as Protein and DNA Carriers. J. Nanopart. Res. 2012, 14 (2), 695-708. (56) Matsuura, K.; Saito, T.; Okazaki, T.; Ohshima, S.; Yumura, M.; Iijima, S. Selectivity of Water-Soluble Proteins in Single-Walled Carbon Nanotube Dispersions. Chem. Phys. Lett. 2006, 429 (4-6), 497-502.

(57) Ge, C.; Du, J.; Zhao, L.; Wang, L.; Liu, Y.; Li, D.; Yang, Y.; Zhou, R.; Zhao, Y.; Chai, Z.; Chen, C. Binding of Blood Proteins to Carbon Nanotubes Reduces Cytotoxicity. Proc. Natl. Acad. Sci. U. S. A. 2011, 108 (41), 16968-16973.

(58) Az'hari, S.; Ghayeb, Y. Effect of Chirality, Length and Diameter of Carbon Nanotubes on the Adsorption of 20 Amino Acids: A Molecular Dynamics Simulation Study. Mol. Simul. 2014, 40 (5), 392398.

(59) Rajesh, C.; Majumder, C.; Mizuseki, H.; Kawazoe, Y. A Theoretical Study on the Interaction of Aromatic Amino Acids with Graphene and Single Walled Carbon Nanotube. J. Chem. Phys. 2009, 130 (12), 124911.

(60) Raffaini, G.; Ganazzoli, F. Protein Adsorption on Biomaterial and Nanomaterial Surfaces: A Molecular Modeling Approach to Study Non-Covalent Interactions. J. Appl. Biomater. Biomech. 2010, 8 (3), $135-145$.

(61) Raffaini, G.; Ganazzoli, F. Surface Topography Effects in Protein Adsorption on Nanostructured Carbon Allotropes. Langmuir 2013, 29 (15), 4883-4893.

(62) Gu, Z.; Yang, Z.; Chong, Y.; Ge, C.; Weber, J. K.; Bell, D. R.; Zhou, R. Surface Curvature Relation to Protein Adsorption for Carbon-Based Nanomaterials. Sci. Rep. 2015, 5, 10886.

(63) Holt, B. D.; McCorry, M. C.; Boyer, P. D.; Dahl, K. N.; Islam, M. F. Not All Protein-Mediated Single-Wall Carbon Nanotube Dispersions Are Equally Bioactive. Nanoscale 2012, 4, 7425-7434.

(64) Nepal, D.; Geckeler, K. E. PH-Sensitive Dispersion and Debundling of Single-Walled Carbon Nanotubes: Lysozyme as a Tool. Small 2006, 2 (3), 406-412.

(65) Verwey, E. J. W. Theory of the Stability of Lyophobic Colloids. J. Phys. Colloid Chem. 1947, 51, 631-636.

(66) Shih, C. J.; Lin, S.; Strano, M. S.; Blankschtein, D. Understanding the Stabilization of Single-Walled Carbon Nanotubes and Graphene in Ionic Surfactant Aqueous Solutions: Large-Scale Coarse-Grained Molecular Dynamics Simulation-Assisted DLVO Theory. J. Phys. Chem. C 2015, 119 (2), 1047-1060.

(67) Edri, E.; Regev, O. Shaken, Not Stable": Dispersion Mechanism and Dynamics of Protein-Dispersed Nanotubes Studied via Spectroscopy. Langmuir 2009, 25 (18), 10459-10465. 
(68) Horn, D. W.; Davis, V. A. Concentration of Lysozyme/singleWalled Carbon Nanotube Dispersions. Colloids Surf., B 2016, 139, 237-243.

(69) Vaitheeswaran, S.; Garcia, A. E. Protein Stability at a Carbon Nanotube Interface. J. Chem. Phys. 2011, 134 (12), 125101.

(70) Calvaresi, M.; Hoefinger, S.; Zerbetto, F. Probing the Structure of Lysozyme-Carbon-Nanotube Hybrids with Molecular Dynamics. Chem. - Eur. J. 2012, 18 (14), 4308-4313.

(71) Asuri, P.; Karajanagi, S. S.; Yang, H.; Yim, T. J.; Kane, R. S.; Dordick, J. S. Increasing Protein Stability through Control of the Nanoscale Environment. Langmuir 2006, 22 (13), 5833-5836.

(72) Cheng, Y.; Liu, G. R.; Li, Z. R.; Lu, C. Computational Analysis of Binding Free Energies between Peptides and Single-Walled Carbon Nanotubes. Phys. A 2006, 367, 293-304.

(73) Murayama, K.; Tomida, M. Heat-Induced Secondary Structure and Conformation Change of Bovine Serum Albumin Investigated by Fourier Transform Infrared Spectroscopy. Biochemistry 2004, 43 (36), $11526-11532$

(74) De Leo, V.; Catucci, L.; Di Mauro, A. E.; Agostiano, A.; Giotta, L.; Trotta, M.; Milano, F. Effect of Ultrasound on the Function and Structure of a Membrane Protein: The Case Study of Photosynthetic Reaction Center from Rhodobacter Sphaeroides. Ultrason. Sonochem. 2017, 35 (Part A), 103-111.

(75) Artyukhin, A. B.; Shestakov, A.; Harper, J.; Bakajin, O.; Stroeve, P.; Noy, A. Functional One-Dimensional Lipid Bilayers on Carbon Nanotube Templates. J. Am. Chem. Soc. 2005, 127 (20), 7538-7542.

(76) Bradley, K.; Davis, A.; Gabriel, J. C. P.; Grüner, G. Integration of Cell Membranes and Nanotube Transistors. Nano Lett. 2005, 5 (5), $841-845$.

(77) El Hadj, K.; Bertoncini, P.; Chauvet, O. pH-Sensitive Photoinduced Energy Transfer from Bacteriorhodopsin to SingleWalled Carbon Nanotubes in SWNT-bR Hybrids. ACS Nano 2013, 7 (10), 8743-8752.

(78) Bertoncini, P.; Chauvet, O. Conformational Structural Changes of Bacteriorhodopsin Adsorbed onto Single-Walled Carbon Nanotubes. J. Phys. Chem. B 2010, 114 (12), 4345-4350.

(79) Hanefeld, U.; Gardossi, L.; Magner, E. Understanding Enzyme Immobilisation. Chem. Soc. Rev. 2009, 38 (2), 453-468.

(80) Karajanagi, S. S.; Vertegel, A. A.; Kane, R. S.; Dordick, J. S. Structure and Function of Enzymes Adsorbed $\backslash$ rSingle-Walled Carbon Nanotubes. Langmuir 2004, 20 (10), 11594-11599.

(81) Kim, J. H.; Ahn, J. H.; Barone, P. W.; Jin, H.; Zhang, J.; Heller, D. A.; Strano, M. S. A Luciferase/single-Walled Carbon Nanotube Conjugate for nearInfrared Fluorescent Detection of Cellular ATP. Angew. Chem., Int. Ed. 2010, 49 (8), 1456-1459.

(82) Dwyer, M. A.; Hellinga, H. W. Periplasmic Binding Proteins: A Versatile Superfamily for Protein Engineering. Curr. Opin. Struct. Biol. 2004, 14 (4), 495-504.

(83) Chen, R. J.; Bangsaruntip, S.; Drouvalakis, K. A.; Kam, N. W. S.; Shim, M.; Li, Y.; Kim, W.; Utz, P. J.; Dai, H. Noncovalent Functionalization of Carbon Nanotubes for Highly Specific Electronic Biosensors. Proc. Natl. Acad. Sci. U. S. A. 2003, 100 (9), 4984-4989.

(84) Nelson, J. T.; Kim, S.; Reuel, N. F.; Salem, D. P.; Bisker, G.; Landry, M. P.; Kruss, S.; Barone, P. W.; Kwak, S.; Strano, M. S. Mechanism of Immobilized Protein A Binding to Immunoglobulin G on Nanosensor Array Surfaces. Anal. Chem. 2015, 87 (16), 81868193.

(85) Chen, R. J.; Zhang, Y.; Wang, D.; Dai, H. Noncovalent Sidewall Functionalization of Carbon Nanotubes for Protein Immobilization. J. Am. Chem. Soc. 2001, 123 (16), 3838-3839.

(86) Besteman, K.; Lee, J.; Wiertz, F. G. M.; Heering, H. A.; Dekker, C. Enzyme-Coated Carbon Nanotubes as Single-Molecule Biosensors. Nano Lett. 2003, 3 (6), 727-730.

(87) Pang, H. L.; Liu, J.; Hu, D.; Zhang, X. H.; Chen, J. H. Immobilization of Laccase onto 1-Aminopyrene Functionalized Carbon Nanotubes and Their Electrocatalytic Activity for Oxygen Reduction. Electrochim. Acta 2010, 55 (22), 6611-6616.

(88) Suma, Y.; Lim, H.; Kwean, O. S.; Cho, S.; Yang, J.; Kim, Y.; Kang, C. S.; Kim, H. S. Enzymatic Degradation of Aromatic
Hydrocarbon Intermediates Using a Recombinant Dioxygenase Immobilized onto Surfactant-Activated Carbon Nanotube. Bioresour. Technol. 2016, 210, 117-122.

(89) Chen, X.; Wang, Y.; Wang, P. Peptide-Induced Affinity Binding of Carbonic Anhydrase to Carbon Nanotubes. Langmuir 2015, 31 (1), 397-403.

(90) Su, Z.; Mui, K.; Daub, E.; Leung, T.; Honek, J. Single-Walled Carbon Nanotube Binding Peptides: Probing Tryptophan's Importance by Unnatural Amino Acid Substitution. J. Phys. Chem. B 2007, 111 (51), 14411-14417.

(91) Holt, B. D.; Dahl, K. N.; Islam, M. F. Quantification of Uptake and Localization of Bovine Serum Albumin-Stabilized Single-Wall Carbon Nanotubes in Different Human Cell Types. Small 2011, 7 (16), 2348-2355

(92) Leeuw, T. K.; Reith, R. M.; Simonette, R. A.; Harden, M. E.; Cherukuri, P.; Tsyboulski, D. A.; Beckingham, K. M.; Weisman, R. B. Single-Walled Carbon Nanotubes in the Intact Organism: Near-IR Imaging and Biocompatibility Studies in Drosophila. Nano Lett. 2007, 7 (9), 2650-2654.

(93) Boyer, P.; Ganesh, S.; Qin, Z.; Holt, B. D.; Buehler, M. J.; Islam, M. F.; Dahl, K. N. Delivering Single-Walled Carbon Nanotubes to the Nucleus Using Engineered Nuclear Protein Domains. ACS Appl. Mater. Interfaces 2016, 8 (5), 3524-3534.

(94) Hashida, Y.; Tanaka, H.; Zhou, S.; Kawakami, S.; Yamashita, F.; Murakami, T.; Umeyama, T.; Imahori, H.; Hashida, M. Photothermal Ablation of Tumor Cells Using a Single-Walled Carbon NanotubePeptide Composite. J. Controlled Release 2014, 173 (1), 59-66.

(95) Green, A. A.; Hersam, M. C. Nearly Single-Chirality SingleWalled Carbon Nanotubes Produced via Orthogonal Iterative Density Gradient Ultracentrifugation. Adv. Mater. 2011, 23 (19), 2185-2190.

(96) Ghosh, S.; Bachilo, S. M.; Weisman, R. B. Advanced Sorting of Single-Walled Carbon Nanotubes by Nonlinear Density-Gradient Ultracentrifugation. Nat. Nanotechnol. 2010, 5 (6), 443-450.

(97) Liu, H.; Nishide, D.; Tanaka, T.; Kataura, H. Large-Scale SingleChirality Separation of Single-Wall Carbon Nanotubes by Simple Gel Chromatography. Nat. Commun. 2011, 2, 309.

(98) Mohamad, N. R.; Marzuki, N. H. C.; Buang, N. A.; Huyop, F.; Wahab, R. A. An Overview of Technologies for Immobilization of Enzymes and Surface Analysis Techniques for Immobilized Enzymes. Biotechnol. Biotechnol. Equip. 2015, 29 (2), 205-220.

(99) Putzbach, W.; Ronkainen, N. J. Immobilization Techniques in the Fabrication of Nanomaterial-Based Electrochemical Biosensors: A Review. Sensors 2013, 13 (4), 4811-4840.

(100) Shen, J.-W.; Wu, T.; Wang, Q.; Kang, Y. Induced Stepwise Conformational Change of Human Serum Albumin on Carbon Nanotube Surfaces. Biomaterials 2008, 29 (28), 3847-3855.

(101) Zhang, B.; Xing, Y.; Li, Z.; Zhou, H.; Mu, Q.; Yan, B.; Shim, M.; Moore, J.; Campbell, P. N. Functionalisation of Carbon Nanotubes for Biocompatability and Biomolecular Recognition. Biochem. Educ. 2002, 6 (2), 285-288.

(102) Neves, L. F. F.; Krais, J. J.; Van Rite, B. D.; Ramesh, R.; Resasco, D. E.; Harrison, R. G. Targeting Single-Walled Carbon Nanotubes for the Treatment of Breast Cancer Using Photothermal Therapy. Nanotechnology 2013, 24 (37), 375104.

(103) Rungnim, C.; Rungrotmongkol, T.; Kungwan, N.; Hannongbua, S. Protein-protein Interactions between SWCNT/ chitosan/EGF and EGF Receptor: A Model of Drug Delivery System. J. Biomol. Struct. Dyn. 2016, 34, 1919-1929.

(104) Ohta, T.; Hashida, Y.; Yamashita, F.; Hashida, M. Sustained Release of Mitomycin C from Its Conjugate with Single-Walled Carbon Nanotubes Associated by Pegylated Peptide. Biol. Pharm. Bull. 2016, 39 (10), 1687-1693. 